\title{
Evaluation of droplet deposition and effect of variable-rate application by a manned helicopter with AG-NAV Guía system
}

\author{
Weixiang Yao ${ }^{1,2}$, Yubin $\operatorname{Lan}^{1,2^{*}}$, Sheng Wen ${ }^{2}$, Huihui Zhang ${ }^{3}$, Yali Zhang ${ }^{1,2}$, \\ Juan Wang ${ }^{1,2,4}$, Chunchun Xie ${ }^{5}$ \\ (1. College of Engineering, South China Agricultural University, Guangzhou 510642, China; 2. National Center for International \\ Collaboration Research on Precision Agricultural Aviation Pesticides Spraying Technology (NPAAC), Guangzhou 510642, China; \\ 3. USDA-Agricultural Research Service, Fort Collins, CO 80526, USA; 4. Mechanical and Electrical Engineering College, Hainan \\ University, Haikou 570228, China; 5. Shandong Ruida Pest Prerention \& Control Co., Ltd, Jinan 250101, China)
}

\begin{abstract}
The variable-rate application is an important aspect of precision agriculture. In order to determine the regular patterns of droplet deposition and compare the actual variable-rate spraying effect of the AS350B3e helicopter with the AG-NAV Guía system, spray tests were conducted with different operating parameters and operating methods. In this study, the deposition distribution of droplets in the effective swath area was evaluated for six single-pass applications at four different flight velocities. The effects of adding adjuvant on droplet deposition, drift and droplet size were compared, and the actual variable effect of the forth-back application was verified. The analysis results showed that the position of the effective swath area was affected by natural wind velocity and wind direction, and would shift to the downwind direction area from the helicopter route of a different degree. The effective swath width increased slowly and then decreased sharply with the increase of flight velocity. It was found that flight velocity of $100 \mathrm{~km} / \mathrm{h}$ was the peak inflection point of effective spray width variation. Moreover, the effect of flight velocity on the distribution uniformity of droplet deposition in the effective swath area was not significant. In the single-pass application of $90 \mathrm{~km} / \mathrm{h}$, adding adjuvant could increase droplet size in the effective swath area. The deposition increased by $8.98 \%$, and the total drift decreased by $28.65 \%$, of which the upwind drift decreased by $28.31 \%$ and the downwind drift decreased by $29.06 \%$. In the forth-back application of $90 \mathrm{~km} / \mathrm{h}$, the error between actual application volume and system setting dose was $12 \%$. The results of this study can provide valuable references for future research and practices on variable-rate aerial applications by manned helicopters.
\end{abstract}

Keywords: manned helicopter, precision agriculture, variable-rate aerial application, spray test, adjuvant, droplet deposition DOI: $10.25165 /$ j.ijabe.20191201.4039

Citation: Yao W X, Lan Y B, Wen S, Zhang H H, Zhang Y L, Wang J, et al. Evaluation of droplet deposition and effect of variable-rate application by a manned helicopter with AG-NAV Guía system. Int J Agric \& Biol Eng, 2019; 12(1): 172-178.

\section{Introduction}

In the 1990s, an aerial variable-rate application system was first used in the United States and then gradually developed ${ }^{[1]}$. An aerial variable-rate application system includes navigation system and variable flow control system that allows variable spray of pesticides, herbicides, soil amendments and fertilizers for specific areas. The research on aerial variable-rate application system started earlier in developed countries and there have been some commercial aerial variable-rate application control systems for manned agricultural

Received date: 2018-03-05 Accepted date: 2018-12-18

Biographies: Weixiang Yao, $\mathrm{PhD}$ candidate, research interests: precision agriculture technology and equipment, Email: 1913835329@qq.com; Sheng Wen, $\mathrm{PhD}$, Associate Professor, research interests: precision agricultural aviation application, Email: 58675023@qq.com; Huihui Zhang, PhD, Research Agricultural Engineer, research interests: airborne and ground-based remote sensing, Email: huihui.zhang@ars.usda.gov; Yali Zhang, PhD, Associate Professor, research interests: precision agricultural aviation application, Email: ylzhang@scau.edu.cn; Juan Wang, PhD candidate, research interests: precision agriculture technology and equipment, Email: 49792740@qq.com; Chunchun Xie, Senior engineer, research interests: application of pesticides in agriculture aerial, Email: rdff@ foxmail.com.

*Corresponding author: Yubin Lan, PhD, Distinguished Professor, research interests: precision agricultural aviation application. College of Engineering, South China Agricultural University, Guangzhou 510642, China. Tel: +86-20-85281421, Email: ylan@scau.edu.cn. aircraft. The common feature of these systems is to provide precision navigation guidance for pilots, and automatically adjust spray flow rate according to the flight parameters during flight ${ }^{[2,3]}$.

In view of the accuracy and practicability of aerial variable-rate application systems, researchers have carried out some exploratory research. Kirk and Tom ${ }^{[4]}$ installed SATLOC Flow Control/ Monitor (AgJunction, Inc., Hiawatha, USA) system on a Cessna AgHusky aircraft (Cessna, Inc., Wichita, USA), and compared the spray uniformity of variable spraying and conventional constant spraying under different meteorological conditions. The test results showed that spray control errors of the flow control system was less than the conventional constant spray errors. Smith ${ }^{[5]}$ evaluated AutoCal I and AutoCal II (Houma Avionics, Inc., Houma, USA) systems with an Air Tractor 402 aircraft (Air Tractor, Inc., Olney, USA). The performance of the two systems was evaluated by experimental and theoretical errors. He found that experimental error was not significantly affected by the application rate in either system, but increased with the number of spray passes. The theoretical error of AutoCal I system gradually increased from $0.79 \%$ to $3.20 \%$. Thomson et al. ${ }^{[6]}$ conducted a comparative test on the flow control reaction speed and accuracy of SATLOC M3 (AgJunction, Inc., Hiawatha, USA) system and improved the control system accordingly. Smith and Thomson $^{[7]}$ also calibrated the GPS positioning accuracy and response time of SATLOC M3 system. It was proved that the 
GPS real-time positioning error was from $0.01 \%$ to $0.11 \%$ while the aircraft was flying in a range of $176 \mathrm{~km} / \mathrm{h}$ to $238 \mathrm{~km} / \mathrm{h}$. Koch et al. ${ }^{[8]}$ compared the economic costs of nitrogen fertilizer spray based on variable-rate and common constant application in specific areas, and indicated that the application of variable-rate technology could reduce the amount of $6 \%-46 \%$ of nitrogen fertilizer and increase the economic incomes of $\$ 18.21-\$ 29.57$ per hectare. Mcleod et al. ${ }^{[9]}$ gave a detailed introduction to the application of aerial variable spraying systems in forest pest control and found that actual droplet deposition area shifted with the direction of natural wind. They also demonstrated how to use the variable spray system to achieve offset compensation for deposition. Priddel et al. ${ }^{[10]}$ installed an AG-NAV Guía (AG-NAV Inc., Barrie, Canada) system on AS350B3 manned helicopter (Eurocopter SA, Marseille, France) to carry out variable-rate aerial baiting for eradication exotic mammals such as mice and rabbits on the southern island of Australia. The system was set at $30 \mathrm{~m}, 70 \mathrm{~m}$ and $80 \mathrm{~m}$ effective swath widths for different sizes of the trapping baits. They sampled every three months after spraying, and finally verified that the effect of variable-rate application was significant.

At present, there is a big gap in aviation spray equipment and core technology research between China and other developed countries ${ }^{[11,12]}$. In China, few scholars are engaged in research on aerial variable-rate technology with agricultural manned helicopter, and most of them concentrate in the field of agricultural unmanned aerial vehicle $(U A V)^{[13-17]}$. $U p$ to now the main spraying application with manned agricultural helicopter in China is still constant rate, in addition, related studies usually focused on pesticides efficacy analysis ${ }^{[18-20]}$. It usually lacks practical assessment of actual application parameters for various helicopters and ancillary equipment after their introduction from foreign countries $^{[21]}$, let alone droplet deposition of variable spraying. Only Zhang et al. ${ }^{[22]}$ designed a control system of variable pesticide application for manned helicopter in China. The results of actual effect comparison showed that when the speed of the helicopter was less than $160 \mathrm{~km} / \mathrm{h}$, the error between the actual application pesticide volume and pesticide application volume set did not exceed $10 \%$. However, this study only verified the effect of the system from the perspective of application volume; droplet deposition and drift situation of variable-rate application by the helicopter were not analyzed.

The objectives of this study were to evaluate the performance parameters of AG-NAV Guía system on an AS350B3e helicopter and provide effective theoretical guidance for the promotion of the variable-rate application system in China.

\section{Materials and methods}

\subsection{Manned helicopter and carrying equipment}

Spray application tests used TR-3 conical nozzles (Lechler Gmbh, Metzingen, Germany). All tests were made using an AS350B3e helicopter, equipped with the AG-NAV Guía system for precision variable-rate spraying control. Simultaneously, an aerial BeiDou positioning UB351 system developed by South China Agricultural University with the function of RTK differential positioning was also equipped ${ }^{[23]}$. The data acquisition interval was $0.1 \mathrm{~s}$ to record flight parameters in real time and draw actual operation trajectory as references for variable-rate spraying effect analyze. The specifications of the helicopter and carrying equipment are listed in Table 1.
Table 1 Specifications of AS350B3e and carrying equipment

\begin{tabular}{|c|c|}
\hline Main parameter & Norms and numerical \\
\hline Type & AS350B3e \\
\hline Length/m & 10.93 \\
\hline Height/m & 3.34 \\
\hline Main/Tail rotor diameter $/ \mathrm{m}$ & $10.69 / 1.06$ \\
\hline Maximum load/L & $600-650$ \\
\hline Maximum velocity $/ \mathrm{km} \cdot \mathrm{h}^{-1}$ & 287 \\
\hline Empty weight $/ \mathrm{kg}$ & 1237 \\
\hline Max.takeoff weight $/ \mathrm{kg}$ & 2250 \\
\hline Boom length/m & 9 \\
\hline Nozzle quantity & 76 (42 single, 17 double) \\
\hline Nozzle orientation & Downward \\
\hline Spray width/m & $30-40$ \\
\hline Pesticide tank size/m & $2.2 \times 1.1 \times 0.3$ \\
\hline Working performance $/ \mathrm{hm}^{2} \cdot \mathrm{h}^{-1}$ & $350-500$ \\
\hline Variable system & AG-NAV Guía \\
\hline BeiDou plane accuracy $/ \mathrm{mm}$ & $\left(10+5 \times \mathrm{D} \times 10^{-7}\right)^{[\mathrm{a}]}$ \\
\hline BeiDou elevation accuracy $/ \mathrm{mm}$ & $\left(20+1 \times \mathrm{D} \times 10^{-6}\right)^{[\mathrm{a}]}$ \\
\hline
\end{tabular}

\subsection{Spray reagent and sample collection card}

The experiment used the mass fraction of $1.25 \%$ urea aqueous solution $400 \mathrm{~L}$ instead of liquid pesticide for spraying, with flying adjuvant Feibao (Shandong Ruida Pest Prerention \& Control Co., Ltd, Jinan, China). The adjuvant volume fraction was $3 \%$, and the main ingredient was vegetable oil and function for anti-evaporation, promoting sedimentation, reducing drift. The sample collection card, $76 \mathrm{~mm} \times 26 \mathrm{~mm}$, was water-sensitive paper (WSP) (Syngenta Crop Protection LLC, Basel, Switzerland).

\subsection{Experimental site and layout}

The experiment was implemented at Shashi Airport $\left(112^{\circ} 17^{\prime} \mathrm{E}\right.$, $\left.30^{\circ} 19^{\prime} \mathrm{N}\right)$ of Jingzhou City, Hubei Province, China. The experiment site was $2000 \mathrm{~m}$ long and $400 \mathrm{~m}$ wide without shelters, and the main spraying area was grassland with a grass height of $15-25 \mathrm{~cm}$. Figure 1 shows how the sample collection cards and application patterns arranged at the spray area. According to the wind direction, the spray area was determined for two sampling lines from east to west (E-W) with $110 \mathrm{~m}$ long and $80 \mathrm{~m}$ spacing. The sampling lines were paralleled to the prevailing wind, and each collection was marked in steps from $-30 \mathrm{~m}$ to $80 \mathrm{~m}(\mathrm{E}-\mathrm{W})$. The helicopter flew south to north (S-N) at the direction perpendicular to the wind direction. The entire test included six single-pass applications (S-N) (1\#-6\#) and two forth-back applications (7\#, 8\#), and the specific test parameters are shown in Table 2. For the single-pass application, the sample collection at the centerline was set as $0 \mathrm{~m}$, and the interval of WSPs was $2 \mathrm{~m}$ in $-30 \mathrm{~m}$ to $40 \mathrm{~m}$ area and $4 \mathrm{~m}$ in $40 \mathrm{~m}$ to $80 \mathrm{~m}$ area. For the forth-back application test, the swath width was set as $30 \mathrm{~m}$, and the interval of WSPs was $4 \mathrm{~m}$ through entire sampling lines.

A Kestrel 5500 Link micro meteorological station (Nielsen-Kellerman Co., Boothwyn, USA) was located at a height of $2 \mathrm{~m}$ above ground and far away from the route. The weather data, such as temperature, humidity, wind velocity and wind direction in the natural environment, were recorded every $5 \mathrm{~s}$ during the experiment. 


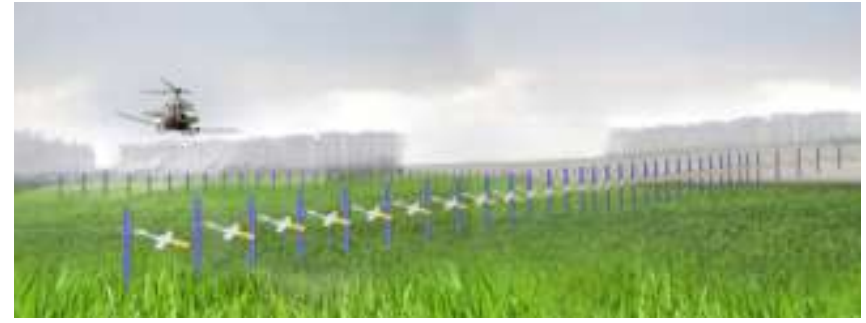

a. Operating effect of AS350B3e

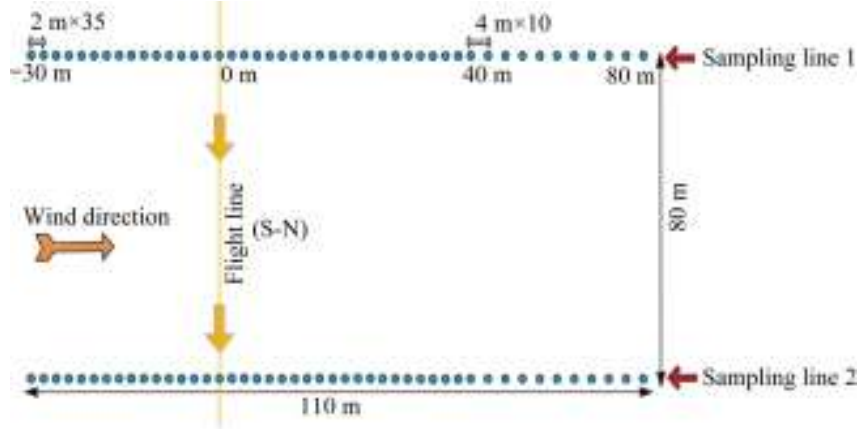

b. Layout of field sampling for single-direction application

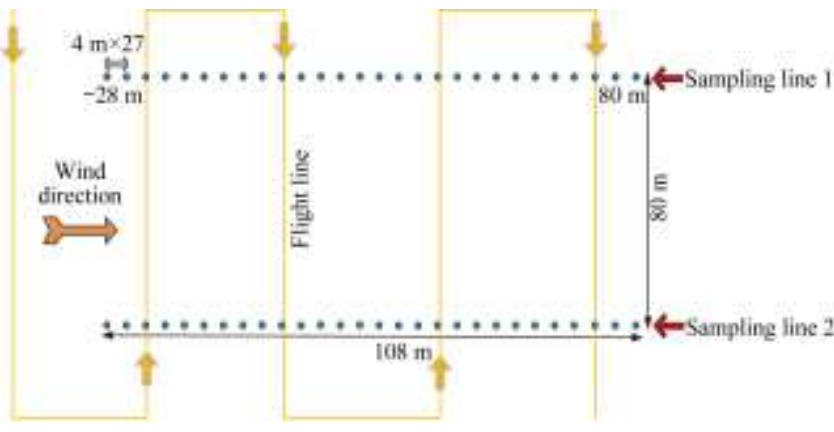

c. Layout of field sampling for forth-back application

Figure 1 Schematic diagram of test

Table 2 Summary of test operation parameters

\begin{tabular}{ccccc}
\hline Test & $\begin{array}{c}\text { Setting flight } \\
\text { velocity/km· } \mathbf{h}^{-1}\end{array}$ & $\begin{array}{c}\text { Setting flight } \\
\text { height/m }\end{array}$ & $\begin{array}{c}\text { Add aviation } \\
\text { adjuvant }\end{array}$ & $\begin{array}{c}\text { Setting spray } \\
/ \mathrm{L} \cdot \mathrm{hm}^{-2}\end{array}$ \\
\hline$\#$ & 90 & 5 & $\mathrm{~N}$ & 12 \\
$2 \#$ & 70 & 5 & $\mathrm{Y}$ & 12 \\
$3 \#$ & 90 & 5 & $\mathrm{Y}$ & 12 \\
$4 \#$ & 90 & 5 & $\mathrm{Y}$ & 12 \\
$5 \#$ & 100 & 5 & $\mathrm{Y}$ & 12 \\
$6 \#$ & 120 & 5 & $\mathrm{Y}$ & 12 \\
$7 \#$ & 90 & 5 & $\mathrm{Y}$ & 12 \\
$8 \#$ & 90 & 5 & $\mathrm{Y}$ & 6 \\
\hline
\end{tabular}

\subsection{Data analysis}

After each spray application test, the WSPs were immediately gathered and put into marked envelopes with disposable gloves and placed in a cool place to be brought back to the laboratory later. Then WSPs were analyzed by using image processing software DepositScan (USDA. Wooster, USA). The deposition, DV0.1, DV0.5, DV0.9, and deposition density of drops per card were determined. Meanwhile, mean deposition, mean deposition density and coefficient of variation (CV) were also calculated.

The DVa values are the droplet diameters $(\mu \mathrm{m})$ where $(\mathrm{a} \times$ 100) $\%$ of the spray volume is accumulated in droplets smaller than this value. The coefficient of variation is used to characterize the uniformity of deposition distribution. The smaller coefficient of variation, the more uniform of droplet deposition distribution is.

\subsection{Statistical analyses}

All the statistical analyses were performed using the Origin Pro
8.5 software (OriginLab, Hampton, USA). Flight velocity was divided into four levels, the mean value were tested in effective swath area for deposition, DV0.5, deposition density, and the effective swath width measured by the WSP was separated by Least-Significant Difference (LSD) multiple test $(\alpha=0.05)$.

\section{Results and discussion}

\subsection{Meteorological data}

The meteorological data for each test are presented in Table 3. Mean temperature, humidity and wind velocity were consistent across all tests. The wind angles varied between $6.1^{\circ}$ and $25.7^{\circ}$ and were well within the $\pm 30^{\circ}$ recommended by the Industrial Standard MH/T 1050-2012 (2012) $)^{[24]}$.

Table 3 Meteorological data measured and calculated for each test

\begin{tabular}{ccccccc}
\hline Test & Time & $\begin{array}{c}\text { Mean } \\
\text { temperature } \\
/{ }^{\circ} \mathrm{C}\end{array}$ & $\begin{array}{c}\text { Mean } \\
\text { humidity } \\
/ \%\end{array}$ & $\begin{array}{c}\text { Wind } \\
\text { velocity } \\
/ \mathrm{m} \cdot \mathrm{s}^{-1}\end{array}$ & $\begin{array}{c}\text { Wind } \\
\text { description }\end{array}$ & $\begin{array}{c}\text { Wind angle } \\
\text { deviation } \\
{ }^{[\mathrm{a}]}\end{array}$ \\
\hline $1 \#$ & $10: 14-10: 15$ & 22.4 & 72.6 & 1.5 & Northeast & 25.7 \\
$2 \#$ & $10: 26-10: 27$ & 21.5 & 73.1 & 1.3 & Northeast & 16.1 \\
$3 \#$ & $10: 32-10: 33$ & 22.1 & 71.1 & 1.6 & Northeast & 14.9 \\
$4 \#$ & $10: 37-10: 38$ & 22.0 & 72.5 & 2.3 & Southeast & 8.6 \\
$5 \#$ & $10: 42-10: 43$ & 21.9 & 71.3 & 1.2 & Southeast & 15.5 \\
$6 \#$ & $10: 47-10: 48$ & 21.8 & 72.8 & 1.1 & Northeast & 6.1 \\
$7 \#$ & $10: 52-10: 55$ & 21.9 & 70.2 & 1.7 & Southeast & 17.4 \\
$8 \#$ & $11: 06-11: 09$ & 22.0 & 71.1 & 1.5 & Southeast & 9.2 \\
\hline Note: ${ }^{[a]}$ Wind angle deviation corresponds to angle of wind relative to sampling
\end{tabular}
line.

\subsection{Analysis of single-pass application}

3.2.1 Operating parameters and track processing

After accurate measurements by aerial BeiDou positioning UB351 system, six single-pass application operations and tracks were in accordance with the set trajectory (Figure 2). The error between actual flight velocity and setting velocity was within 6 $\mathrm{km} / \mathrm{h}$, and the mean actual flight height was $5.03 \mathrm{~m}$ with the $\mathrm{CV}$ of $6.58 \%$. It can be confirmed that the actual operating parameters met the requirements of the test design.

3.2.2 Effective swath and corresponding deposition effect

To determine the effective swath, the research methods of M-18B and Thrush $510 \mathrm{G}^{[25]}$ and Industrial Standard MH/T 1040-2011 (2011) ${ }^{[26]}$ were referred. We took the half deposition of the maximum peak of a single-pass distribution as a judging standard, and the calculated droplet deposition, distribution uniformity, and corresponding sampling points of the effective swath start and end positions of each test were recorded, as showed in Figure 3.

In Figure 3, the horizontal axis represents collection position of the sampling line. The upper color ribbon indicates actual effective swath area measured in the single-pass application tests, and each color indicates a type of operating parameter. At the same ribbon, the depth of color characterizes the amount of droplet deposition. The deeper the color, the greater the deposition is In the dashed box, $\mathrm{V}$ and $\mathrm{H}$ indicate the flight velocity and height of the helicopter flying over the sampling line. CV indicates the uniformity of the deposition distribution in the effective swath area.

All vehicles overlap area of effective swath was $-8 \mathrm{~m}$ to $12 \mathrm{~m}$. The most effective swath area was shifted downward along the wind direction, with upwind to the farthest starting position of $-16 \mathrm{~m} \mathrm{(3 \# )}$ and downwind to the farthest ending position of $24 \mathrm{~m}$ (5\#). It was found that the shifts of effective swath area were 

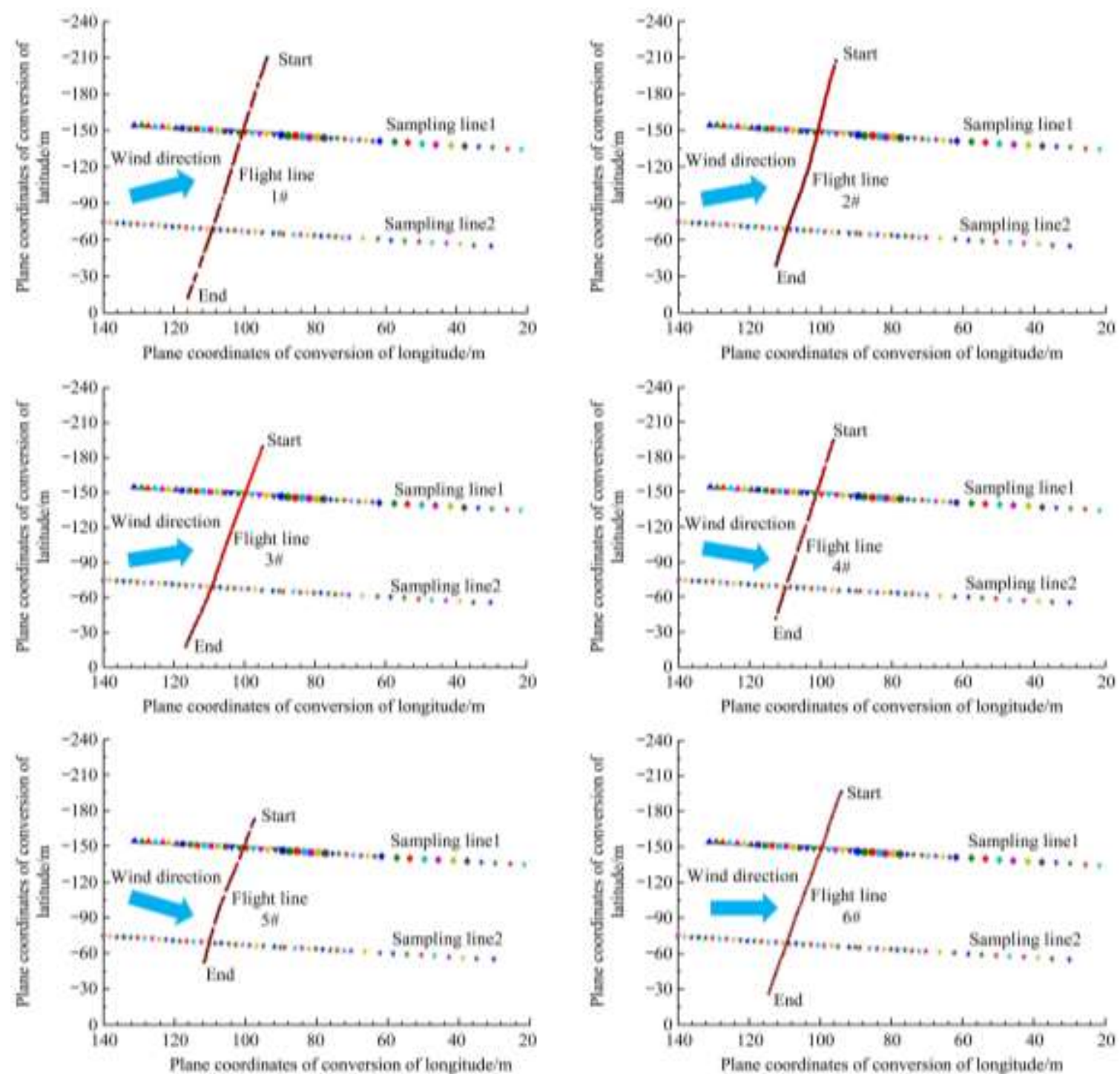

Figure 2 1\#-6\# droplet collection points and flight trajectory

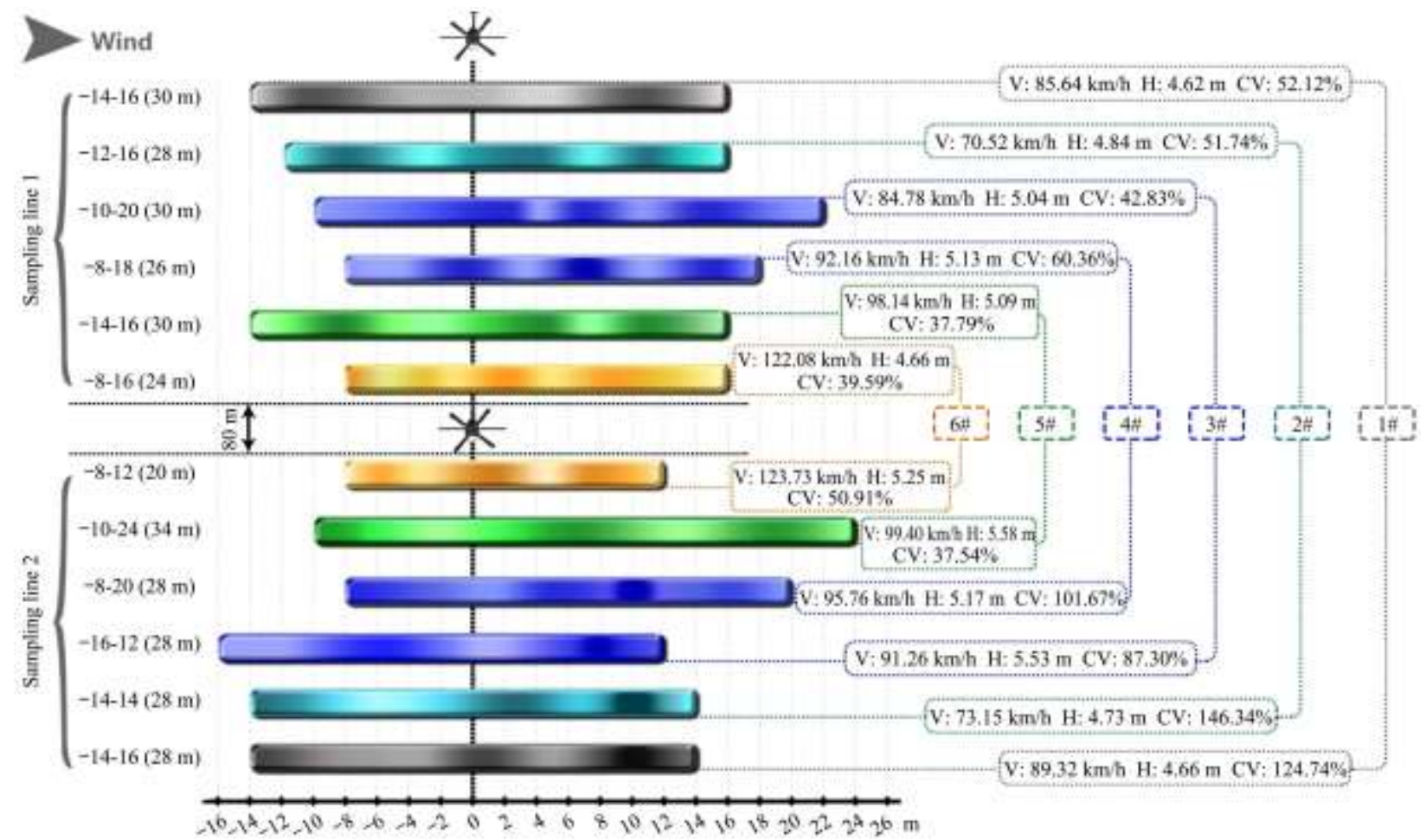

Figure 3 Effective swath and corresponding deposition effect of single-pass application 
caused by the differences of natural wind velocity and wind direction in each test by comparing with the meteorological data. At the meantime, the flight velocity also impacted on the difference of effective swath width, the effective swath width of $2 \#(70 \mathrm{~km} / \mathrm{h})$, $3 \#(90 \mathrm{~km} / \mathrm{h}), 4 \#(90 \mathrm{~km} / \mathrm{h}), 5 \#(100 \mathrm{~km} / \mathrm{h}), 6 \#(120 \mathrm{~km} / \mathrm{h})$ were $28 \mathrm{~m}, 29 \mathrm{~m}, 27 \mathrm{~m}, 32 \mathrm{~m}$, and $22 \mathrm{~m}$, respectively. With the increase of flight velocity, the effective swath width increased slowly but then decreased sharply. The flight velocity of $100 \mathrm{~km} / \mathrm{h}$ was the peak inflection point of effective spray width variation. When the operating height was $5 \mathrm{~m}$, the operating velocity of $90-100 \mathrm{~km} / \mathrm{h}$ should be selected because the effective swath width is relatively large and stable under these circumstances.

In sampling line 2, the CV of 2\#, 3\# and 4\# was $146.34 \%$, $87.30 \%$ and $101.67 \%$, respectively, which was the worst of uniformity. The main reason for this phenomenon was that the helicopter had a rotor vortex and lower wind field was unevenly distributed $^{[27]}$. The droplet deposition was susceptible to turbulence resulting in depositions at $8 \mathrm{~m}(2 \#), 10 \mathrm{~m}(3 \#),-8 \mathrm{~m}$ (4\#) and $10 \mathrm{~m} \mathrm{(4 \# )} \mathrm{were} \mathrm{unusually} \mathrm{large,} \mathrm{thus} \mathrm{CV} \mathrm{was} \mathrm{affected.} \mathrm{It} \mathrm{can}$ be seen that the study of relationship between wind field and distribution of droplet deposition should be strengthened so that the optimal operating parameters can be selected reasonably for different operating environments.

The results of LSD's multiple range tests in each effective swath for deposition, $\mathrm{D}_{\mathrm{V} 0.5}$, deposition density and effective swath are given in Table 4.

Table 4 LSD's multiple range test in each effective swath for deposition, $D_{\mathrm{v} 0.5}$, deposition density and effective swath

\begin{tabular}{ccccc}
\hline Treatment & Deposition $^{\text {[a] }}$ & D $_{\mathrm{V} 0.5}$ & Deposition density & Effective swath \\
\hline $70 \mathrm{~km} / \mathrm{h}$ & $\mathrm{a}$ & $\mathrm{a}$ & $\mathrm{d}$ & $\mathrm{a}$ \\
$90 \mathrm{~km} / \mathrm{h}$ & $\mathrm{ab}$ & $\mathrm{a}$ & $\mathrm{b}$ & $\mathrm{a}$ \\
$100 \mathrm{~km} / \mathrm{h}$ & $\mathrm{b}$ & $\mathrm{ab}$ & $\mathrm{c}$ & $\mathrm{a}$ \\
$120 \mathrm{~km} / \mathrm{h}$ & $\mathrm{c}$ & $\mathrm{b}$ & $\mathrm{a}$ & $\mathrm{b}$ \\
\hline
\end{tabular}

Note: ${ }^{[a]}$ Column means with the same letter are not significantly different.

\subsubsection{Effect of adding adjuvant}

Among the six single-pass application tests, only $1 \#$ was set with the flying velocity of $90 \mathrm{~km} / \mathrm{h}$ and without adding adjuvant. Referring to the actual weather conditions and flight parameters, $3 \#$ and $1 \#$ were most similar expect for adding adjuvant, so the two were chosen to compare the effect of adding adjuvant.

It can been seen from Figure 3 that the effective swath width of $1 \#$ for each sampling line was $30 \mathrm{~m}$ and $28 \mathrm{~m}$, and the effective swath width of $3 \#$ for each sampling line was $30 \mathrm{~m}$ and $28 \mathrm{~m}$, too, which indicates that the effect of adding adjuvant on effective swath width is not obvious. As shown in Figure 4, the mean deposition and uniformity of $1 \#$ was $0.167 \mu \mathrm{L} / \mathrm{cm}^{2}$ and $88.43 \%$, while the mean deposition and uniformity of $3 \#$ was $0.182 \mu \mathrm{L} / \mathrm{cm}^{2}$ and $65.07 \%$, respectively, in the effective swath area. The deposition after adding adjuvant increased by $8.98 \%$, which demonstrates that adjuvant was helpful for increasing deposition and producing deposition more uniformly. As shown in Figure 5, the mean $\mathrm{D}_{\mathrm{V} 0.1}, \mathrm{D}_{\mathrm{V} 0.5}, \mathrm{D}_{\mathrm{V} 0.9}$ and deposition density of 1 \# were $237.56 \mu \mathrm{m}, 397.35 \mu \mathrm{m}, 607.17 \mu \mathrm{m}$, and $14.91 / \mathrm{cm}^{2}$, respectively; while the mean $\mathrm{D}_{\mathrm{v} 0.1}, \mathrm{D}_{\mathrm{v} 0.5}, \mathrm{D}_{\mathrm{v} 0.9}$ and deposition density of 3\# were $247.93 \mu \mathrm{m}, 424.42 \mu \mathrm{m}, 628.89 \mu \mathrm{m}$, and $13.23 / \mathrm{cm}^{2}$, respectively in the effective swath area. The difference in deposition density was not much, but the droplet size of $3 \#$ was greater than the droplet size of 1\#. Therefore, the droplet size increased after adding adjuvant, but the influence of adding adjuvant for deposition density was small.

The total drift of $3 \#$ decreased by $28.65 \%$ after adding adjuvant compared with $1 \#$, of which the upwind drift decreased by $28.31 \%$, and the downwind drift decreased by $29.06 \%$ (Figure 6). This approved that the use of adjuvant was useful for mitigating drift.

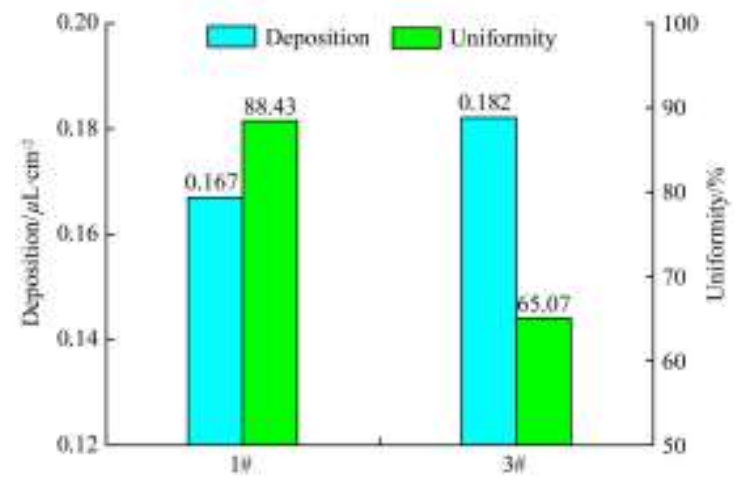

Figure 4 Comparison of mean deposition and mean distribution uniformity for the use of adjuvant

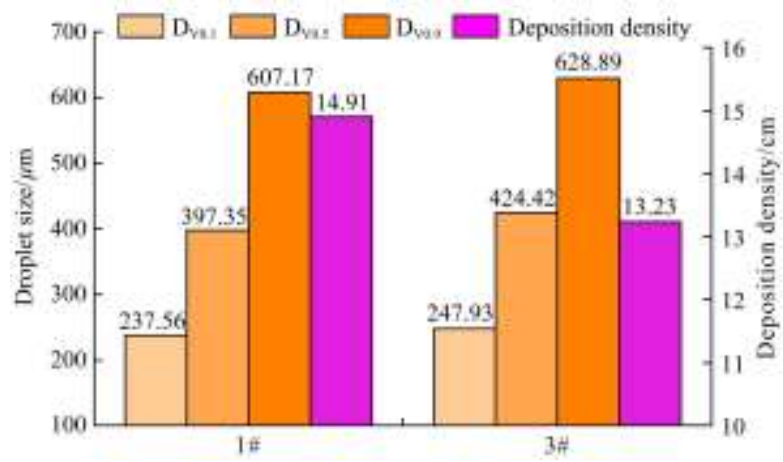

Figure 5 Comparison of mean droplet size and mean deposition density for the use of adjuvant
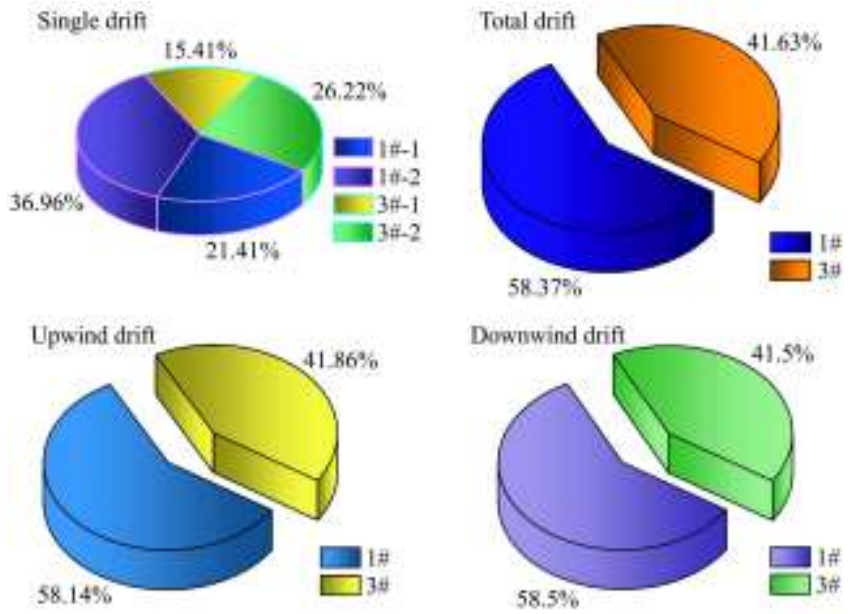

Note: $m \#-n$ indicates the sampling line $n$ of $m \#$.

Figure 6 Statistical analysis of the 1\# and 3\# droplet drift situation

\subsection{Analysis of forth-back application}

\subsubsection{Operating parameters and trajectory processing}

The trajectories of two forth-back application are shown in Figure 7. The Industrial Standard MH/T 1040-2011 (2011) ${ }^{[26]}$ was referred to determine deposition effect of forth-back application. The data of the area between the second and fourth passes were chosen to be analyzed for a distribution model with five passes. Combined with the test design swath width of $30 \mathrm{~m}$, we chose $-20 \mathrm{~m}$ to $40 \mathrm{~m}$ as a research area. The flight parameters of $7 \#$ and $8 \#$ in research area are showed in Table 5. 

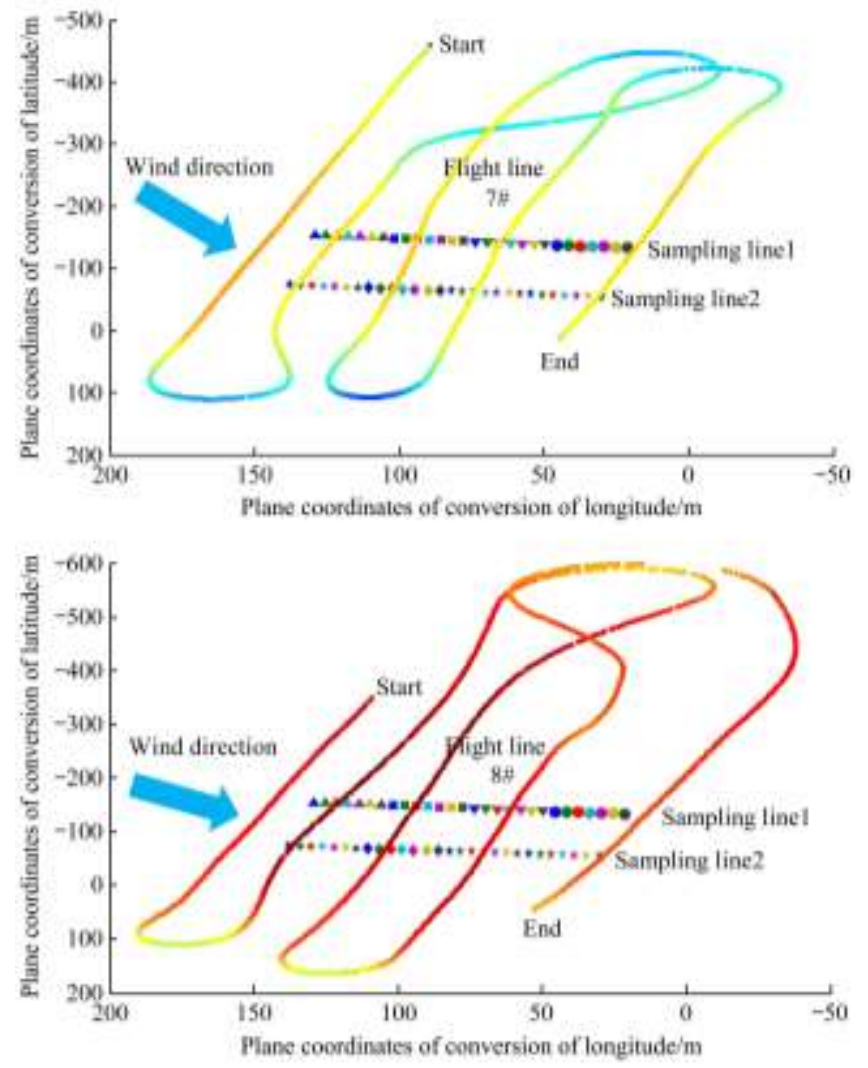

Figure 7 7\#-8\# Droplet collection point and flight trajectory

Table 5 Summary of flight operation parameters in research area

\begin{tabular}{cccc}
\hline \multicolumn{2}{c}{ Flight data } & Flight velocity $/ \mathrm{km} \cdot \mathrm{h}^{-1}$ & Flight height $/ \mathrm{m}$ \\
\hline \multirow{2}{*}{$7 \#$} & Pass 2 & 90 & 5.67 \\
& Pass 3 & 92 & 3.83 \\
& Pass 4 & 89 & 6.50 \\
\hline \multirow{2}{*}{$8 \#$} & Pass 2 & 110 & 4.69 \\
& Pass 3 & 105 & 5.65 \\
& Pass 4 & 93 & 6.56 \\
\hline
\end{tabular}

3.3.2 Effect of total spray volume

In forth-back applications, a total spray volume of $12 \mathrm{~L} / \mathrm{hm}^{2}$ and $6 \mathrm{~L} / \mathrm{hm}^{2}$ were set for $7 \#$ and $8 \#$, respectively. Figure 8 shows that: the mean $\mathrm{D}_{\mathrm{V} 0.1}, \mathrm{D}_{\mathrm{v} 0.5}, \mathrm{D}_{\mathrm{v} 0.9}$ and deposition density of $7 \#$ were $237.77 \mu \mathrm{m}, 427.03 \mu \mathrm{m}, 656.42 \mu \mathrm{m}$, and $19.09 / \mathrm{cm}^{2}$, respectively, while the mean $\mathrm{D}_{\mathrm{v} 0.1}, \mathrm{D}_{\mathrm{v} 0.5}$ and $\mathrm{D}_{\mathrm{v} 0.9}$ and deposition density of $7 \#$ were $210.06 \mu \mathrm{m}, 366.85 \mu \mathrm{m}, 558.53 \mu \mathrm{m}$, and $15.07 / \mathrm{cm}^{2}$, respectively. Clearly, the droplet size and deposition density of $7 \#$ were greater than the droplet size and deposition density of $8 \#$.

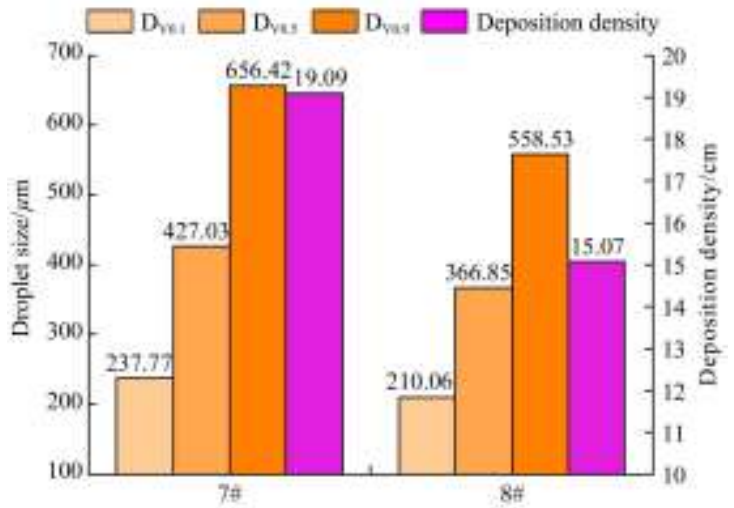

Figure 8 7\#-8\# Comparison of mean droplet size and mean deposition density in research area
As shown in Figure 9, deposition of $7 \#$ and $8 \#$ were significantly different. The mean deposition amount of droplet measured of 7\# was $0.237 \mu \mathrm{L} / \mathrm{cm}^{2}$, and the mean droplet deposition measured of $8 \#$ was $0.135 \mu \mathrm{L} / \mathrm{cm}^{2}$. The former was 1.76 times of the latter, namely the error between actual application volume and system setting dose was $12 \%$, but the trends of two deposition curves were different. The reasons for this situation are:

1) As shown in Table 5, the overall flight velocities of $7 \#$ were stable, but the flight heights of pass 3 and pass 4 changed in a large degree. The pass 2 and pass 3 flight height of $8 \#$ were stable, but the pass 4 changed greatly. The flight velocity of pass 2 , and pass 3 also changed in a large degree for setting parameters. Flight velocity and height are the main factors that affect spray deposition, so difference between the velocity and height of each flight pass during forth-back application was the main reason that caused different spray effects.

2) Furthermore, natural wind velocity and direction were constantly changing in actual application (Table 3). $7 \#$ was southeast wind with the mean wind velocity of $1.7 \mathrm{~m} / \mathrm{s}$ and wind angle of $17.4^{\circ}$; while $8 \#$ was southeast wind with the mean wind velocity of $1.5 \mathrm{~m} / \mathrm{s}$ and wind angle of $9.2^{\circ}$. The effect of spraying in flying applications is particularly affected by natural wind.

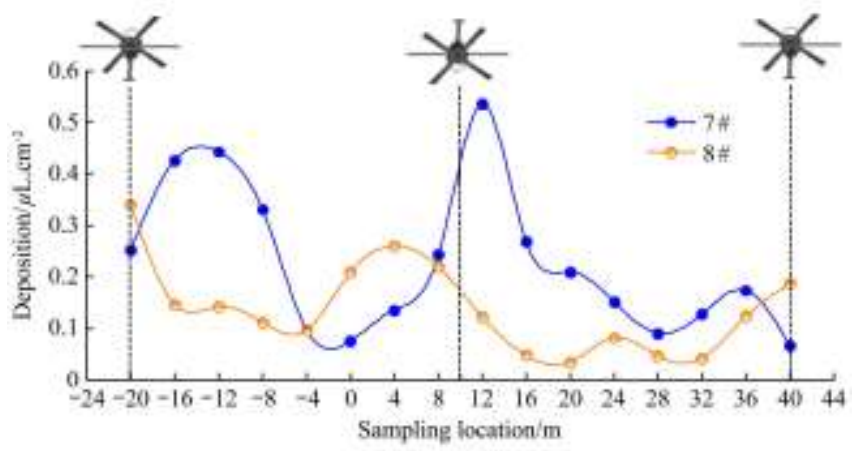

Figure 9 7\#-8\# Comparison of deposition in the research area

\section{Conclusions}

In this research, the regular patterns of droplet deposition and actual variable-rate spraying effect applied by the AS350B3e helicopter with the AG-NAV Guía system were evaluated when the helicopter was operated in different operating parameters and methods. The results illustrated that the position of effective swath area was affected by natural wind velocity and wind direction, and the width of effective swath was affected by flight velocity. When the helicopter was operated at the height of $5 \mathrm{~m}$ and the flight velocity increased from $70 \mathrm{~km} / \mathrm{h}$ to $120 \mathrm{~km} / \mathrm{h}$, the effective swath width increased slowly and then decreased sharply. Due to the presence of rotor vortex, the droplet distribution uniformity was susceptible; it was easy to form a larger deposition on 8-10 m both sides of the centerline. Adding adjuvant could increase droplet size and uniformity in the effective swath area, while increase $8.98 \%$ of the deposition and reduce $28.65 \%$ of the drift. In addition, in the analysis of total spray volume changing by the AG-NAV Guía system, the variable effect was significant, and the error between actual application volume and system setting dose was just $12 \%$. The results and data of this study will be valuable references for future variable-rate aerial applications by manned helicopters in China.

\section{Acknowledgments}

We deeply thank for the financial support given by the 
Guangdong Leading Talent Project (2016LJ06G689), National Key Technologies Research and Development Program (2016YFD0200700), 111 Project (D18019), Guangdong Leading Talent Project (2016LJ06G689), Educational Commission of Guangdong Province of China for Platform Construction and (2015KGJHZ007), Science and Technology Planning Project of Guangdong (2017B010117010). Thanks the National Center for International Collaboration Research on Precision Agricultural Aviation Pesticides Spraying Technology for the full participation persons of the experiment (Yue Changquan, Wang Guobin, Huang Cong). Thanks to Shandong Ruida Pest Prerention \& Control Co., Ltd for strong support.

\section{[References]}

[1] Lan Y B, Thomson S J, Huang Y B, Hoffmann W C, Zhang H H. Current status and future directions of precision aerial application for site-specific crop management in the USA. Computers \& Electronics in Agriculture, 2010; 74(1): 34-38.

[2] Stevenj T, Huang Y B, Jamese H, Daniele M, Lowreya S. Improving flow response of a variable-rate aerial application system by interactive refinement. Computers \& Electronics in Agriculture, 2010; 73(1): 99-104.

[3] Xue X Y, Lan Y B. Agricultural aviation applications in USA. Transactions of the CSAM, 2013; 44(5): 194-201. (in Chinese)

[4] Kirk I W, Tom H H. Precision GPS flow control for aerial spray applications. Precision Agriculture, 1996; 3: 815-817.

[5] Smith L A. Automatic flow control for aerial application. Applied Engineering in Agriculture, 2000; 17(4): 449-455.

[6] Thomson S J, Smith L A, Hanks J E. Evaluation of application accuracy and performance of a hydraulically operated variable-rate aerial application system. Transactions of the ASABE, 2009; 52(3): 715-722.

[7] Smith L A, Thomson S J. GPS position latency determination and ground speed calibration for the SATLOC Airstar M3. Applied Engineering in Agriculture, 2005; 21(5): 769-776.

[8] Koch B, Khosla R, Frasier W M, Westfall D G, Inman D. Economic feasibility of variable-rate nitrogen application utilizing site-specific management zones. Agronomy Journal, 2004; 96(6): 1572-1580.

[9] McLeod I M, Lucarotti C J, Hennigar C R, MacLean D A, Holloway A G L, Cormier G A, et al. Advances in aerial application technologies and decision support for integrated pest management. Integrated Pest Management and Pest Control-Current and Future Tactics, 2012; pp.651-668.

[10] Priddel D, Carlile N, Wilkinson I, Wheeler R. Eradication of exotic mammals from offshore islands in New South Wales, Australia. IUCN, 2011; pp.107-114.

[11] Zhou Z Y, Zang Y, Luo X W, Lan Y B, Xue X Y. Technology innovation development strategy on agricultural aviation industry for plant protection in China. Transactions of the CSAE, 2013; 29(24): 1-10. (in Chinese)

[12] Lan Y B. Agricultural applications of unmanned aerial vehicle. $\mathrm{Zi}$ Guangge, 2017; 1: 86.

[13] Liu Y, Gu C Y. The airborne aeronautical chart assisting navigation system based on component GIS. Geomatics \& Spatial Information Technology, 2009; 6: 87-89, 92. (in Chinese)

[14] Lu Z H, Shen M X, Ji C Y. Channel planning and border algorithm in agricultural aircraft operating based on embedded and GPS technology. Journal of Anhui Agricultural, 2009; 8: 3819-3820, 3823. (in Chinese)

[15] Xu X, Xu S, Liu Y X, Chen J S, Cai Z X, Yu Z S. Variable pesticide spraying system design based on small UAV. Guangdong Agricultural Sciences, 2014; 9: 207-210. (in Chinese)

[16] Wang L, Lan Y B, Hoffmann W C, Bradley K F, Chen D, Wang S M. Design of variable spraying system and influencing factors on droplets deposition of small UAV. Transactions of the CSAM, 2016; 1: 15-22. (in Chinese)

[17] Xue X Y, Lan Y B, Sun Z, Chang C, Hoffmann W C. Develop an unmanned aerial vehicle based automatic aerial spraying system. Computers \& Electronics in Agriculture, 2016; 128: 58-66.

[18] Huang W Z, Lin X A, Cao Q, Qin Y Y. Preliminary report on the experiment of spraying biological agents to control locust locus. Journal of Henan Forestry Science and Technology, 2006; 4: 16-18.

[19] Zhong L, Qiu G H, Song J H, Shi J M, Xu F F, Zhu Q Q, et al. The effect of droplet deposition on the control of rice sheath blight. China Plant Protection, 2014; 8: 64-66. (in Chinese)

[20] Yan R K, Wu N, Hu W J, Wang H E. Experimental report on the control of chromaphis juglandicola kaltenbach by R44Raven- II type of helicopter. Journal of Green Science and Technology, 2016; 3: 4-6. (in Chinese)

[21] Zhang D Y, Lan Y B, Chen L P, Wang X, Liang D. Current status and future trends of agricultural aerial spraying technology in China. Transactions of the CSAM, 2014; 45(10): 53-59. (in Chinese)

[22] Zhang R R, Li Y, Yi T C, Chen L P. Design and experiments of control system of variable pesticide application for manned helicopter. Journal of Agricultural Mechanization Research, 2017; 10: 124-127. (in Chinese)

[23] Lan Y B, Chen S D, Li J Y, Zhang Y L, Huang C, Yao W X, et al. Evaluation system of flying flight quality based on BeiDou locating system. Chinese Patent, CN205563277U.

[24] MH/T Standards. 1050-2012: Field measurement methods for Aircraft spray drift, Beijing: MHT, 2012. (in Chinese)

[25] Zhang D Y, Chen L P, Zhang R R, Xu G, Lan Y B, Wesley C H, et al. Evaluating effective swath width and droplet distribution of aerial spraying systems on M-18B and Thrush $510 \mathrm{G}$ airplanes. Int J Agric \& Biol Eng, 2015; 8(2): 21-30

[26] MH/T Standards. 1040-2011: Determining application rates and distribution patterns from aerial application equipment, Beijing: MHT, 2011. (in Chinese)

[27] Zhu Y. Calculation of aerodynamic interactions between helicopter rotor and fuselage. Nanjing University of Aeronautics \& Astronautics, 2007. (in Chinese) 